\section{HAZARDS OF STEROID TREATMENT}

\author{
BY
}

\section{WILLIAM TEGNER, B.M., F.R.C.P.}

\section{From the Department of Physical Medicine, London Hospital (the North-East Metropolitan Regional Rheumatism Centre)}

The place of steroid drugs in the treatment of rheumatoid arthritis remains a topic of discussion and dissension. Although eleven years have elapsed since their introduction, there is still a great deal of disagreement on such points as indications for their use and their correct dosage. Most physicians who have gained experience in their use prescribe them with great caution, and regard the making of the decision to use steroids as one needing very careful thought and the acceptance of a heavy responsibility. Since these drugs have become available through the National Health Service it has been our experience that on the whole general practitioners have been very cautious about their administration. On the other hand, we have been disturbed during recent months by the number of patients who, having been put on steroids, have not been adequately supervised and who have been permitted, if not encouraged, to take large doses of these potentially dangerous drugs.

In orthodox practice. physicians experienced in the management of arthritic patients do not consider routine prescription of steroids immediately a diagnosis of rheumatoid arthritis has been made. Indeed, it is usual to try various remedies such as bed rest, full doses of salicylate. gold, and the antımalarials before having to consider the possibility of using steroids. It is our teaching at this hospital that steroids, far from being the first weapon of attack against rheumatoid arthritis, should be regarded as the last line of defence against it.

Certain principles must guide the exhibition of steroids. Firstly, they must not be prescribed in doses great enough completely to suppress the activity of the arthritis. It has been our experience that such dosage, while masking the activity of the arthritis, almost inevitably leads to disaster. Secondly, patients must not be allowed to adjust their own dosage as they might be permitted to do with such a relatively harmless drug as salicylate. We have met patients who have been told to take up to $30 \mathrm{mg}$. of prednisone a day according to how they feel. The consequences have been most unfortunate. For in addition to their acquiring the habit of taking steroids, they may well become insensitive to their effects and thereforo demand bigger doses, becoming grotesquely round-faced and obese. Behind the façade of Cushing's syndrome lurk the very real dangers of vertebral collapse, peptic ulceration with bleeding, and hypertension. A failure to take and appreciate a careful history of previous health leads to the very real danger of reactivation of a tuberculous focus or a peptic ulcer. Sudden cessation of steroid therapy or sudden changes in dose or type of steroid are also recognized as factors in the production of a peripheral neuropathy in established rheumatold arthritis-a complication which is not infrequently fatal (Mason and Steinberg, 1958 ; Hart and Golding, 1960).

\section{Case Reports}

Case 1.-The patient was a married man aged 44, with seven children. He developed pulmonary tuberculosis in 1948 , was in a sanatorium for one year, and needed readmission in 1954 and 1958 for further anti-tuberculosis treatment. Eighteen months before admission to the London Hospital he developed a polyarthritis. This was diagnosed as rheumatoid arthritis elsewhere, and he was immediately placed on methylprednisolone $16 \mathrm{mg}$. daily. This was gradually reduced to $4 \mathrm{mg}$., but his joints relapsed and he was put back on $16 \mathrm{mg}$. daily. He still complained of joint pains on this dose, and he was eventually taking $32 \mathrm{mg}$. of methylprednisolone daily. His general practitioner, however, was not satisfied with his progress and referred him to the London Hospital. He had been regularly attending his local chest clinic, his last visit there occurring two weeks before his admission, but the chest physicians were unaware that he was taking steroids. On admission he had a full red face, but clinically there was little evidence of arthritis. Investigations showed: $\mathrm{Hb}, 102 \%$; E.S.R., $12 \mathrm{~mm}$. in one hour (Westergren); latex test, positive $1: 10.240$. $X$-ray films of his joints showed a few erosions of both fifth metatarsal heads. Otherwise the joints appeared normal. $X$-ray examination of his chest, however, suggested bilateral active apical tuberculosis. His sputum was found to contain profuse acid-fast bacilli.

Case 2.-A business-man aged 48 had a three-year history of rheumatoid arthritis. As soon as the diagnosis was made he was placed on prednisolone at his local hospital, the dosage being steadily increased until he was taking $30 \mathrm{mg}$. daily. He remained on that dose for 18 months with little pain from his joints, but at the end of this period started developing backache, which steadily became worse and spread round to the front of the chest and abdomen. He became extremely obese and found that he was losing height, at the time of admission being 5 in. $(12.5 \mathrm{~cm}$.) shorter than his normal height. Just before admission he also complained of numbness and tingling of both arms. On examination there was little sign of arthritis. His appearance was grossly Cushingoid, with a red swollen face, a " buffalo hump," and pitting oedema of the ankles. There was also weakness and wasting of the proximal limb musculature. His blood-pressure was $180 / 120$. Investigations showed: Hb, $74 \%$; E.S.R. $78 \mathrm{~mm}$. in one hour (Westergren); latex test, positive $1: 5,120$. $X$-ray films of the hands and feet revealed no changes of rheumatoid arthritis. $X$-ray examination of the spine showed gross generalized osteoporosis, marked widening of the disk spaces, and partial collapse of several vertebrae in the dorsal spine.

Case 3.-A housewife aged 52 first developed rheumatoid arthritis seven years previously. The course was only slowly progressive and she improved considerably after gold therapy, given four years after the onset of the disease. It was found that both aspirin and phenylbutazone caused marked gastric irritation. She also had much trouble with bleeding haemorrhoids. Eighteen months before admission her arthritis relapsed and she was placed on prednisolone by her general practitioner. She was told to take up to six tablets daily, depending on how much pain she was getting. Her arthritis improved, but she complained of indigestion and was eventually referred to this department. On examination she was found to be markedly Cushingoid in appearance. Her joints showed moderate changes of rheumatoid arthritis. Hb, $84 \%$; E.S.R., $17 \mathrm{~mm}$. in one hour (Westergren); latex test positive. Shortly after admission she had a haematemesis, and a barium-meal examination later showed a filling defect on the posterior gastric wall.

Case 4.-A woman aged 53 presented a different kind of problem in that she had long-standing rheumatoid arthritis, with an onset 27 years previously. In spite of progressive deformities she was able to do light housework and had never needed admission to hospital. Nine months before admission she had orthopaedic operations on her left hand 
to correct severe flexion deformities. They were successful, but while away at a convalescent home she had a slight flare-up of arthritis in her knees and was placed on prednisolone $15 \mathrm{mg}$. daily. This had little effect on her arthritis, but from this time her general condition deteriorated. She developed recurrent attacks of diarrhoea and vomiting. Owing to inadequate indoctrination at the onset of steroid administration, she abruptly stopped taking prednisolone and quite suddenly developed a peripheral neuropathy affecting all four limbs, with bilateral foot-drop and sensory loss over the hands, forearms, feet, and ankles. This has only slightly improved and she is now a severely disabled woman, completely confined to a wheel-chair.

\section{Management}

The management of these unfortunate patients presents many difficulties. In some ways they are addicted, as they have experienced the original joys of steroid euphoria and have come to rely on steroids. We have found that they must have the situation explained to them carefully. They have to be told that steroids in doses in which they are taking them can have very serious, even fatal, side-effects. Their steroid dose is then reduced slowly. With each case this has been done under careful supervision in hospital. In each case there has been some activity of the suppressed arthritis which has needed careful management, but, on the whole, these patients have been co-operative and the treatment successful. It is often surprising how mild the residual arthritis turns out to be, once steroids have been withdrawn.

\section{Conclusion}

The freedom of the physician to choose whichever treatment he feels is best for the patient is of paramount importance. Nevertheless, certain points regarding the use of steroids in rheumatoid arthritis should be emphasized. The patient should be given a clear idea of why the decision to use steroids has been made and must understand that they must be used cautiously under continual medical supervision. The disease process cannot be completely suppressed without grave risk of dangerous side-effects, and long-term high dosage is hazardous. Abrupt withdrawal of the drug is equally dangerous as it raises the risk of adrenal insufficiency. Steroids should not be administered prematurely, and their type and dosage should not be changed haphazardly. Finally, steroids should not be administered prematurely or as the first line of treatment.

I am indebted to Dr. Michael Mason and Dr. Gilson Wenley for their help and advice in writing this paper.

\section{REFERENCES}

Hart, F. D., and Golding, J. R. (1960). Brit. med. J., 1, 1594. Mason, R. M., and Steinberg, V. L. (1958). Ann. phys. Med., 4,265 .

The Committee for Research into Apparatus for the Disabled took a stand at this year's Production Exhibition at Olympia from April 30 to May 5. A machine called Possum (Patient Operated Selector Mechanism) was demonstrated which, when breathed into in the correct manner, can operate the telephone, ring bells, turn on the T.V., switch off the light, type a letter, or perform any one of a number of functions without any movement on the part of the operator other than breathing.

\section{THE CASE AGAINST GASTRECTOMY WITH Y-ANASTOMOSIS IN TREATMENT OF PEPTIC ULCER}

\section{A REPORT OF 50 CASES}

BY

\section{DEREK G. LAMBLEY, M.B., B.Sc., F.R.C.S. Northampton General Hospital}

The $\mathbf{Y}$-anastomosis originally described by Wölfler in 1883 but usually attributed to Roux (1897) has for many years fallen into disrepute because of its frequent association with anastomotic ulcer. However, it has been used in the past in gastroenterostomy alone, or with a very low gastric resection, and before the modern principles of gastric resection had been introduced. Schofield and Anderson (1953) reported a series of cases in which they had performed gastrectomy using the $Y$ form of anastomosis. They made no claim that the operation was as safe from recurrent ulceration as was the Polya type of procedure, but did claim an absence of the dumping syndrome in their cases treated by $\mathrm{Y}$-anastomosis. Conversion in three cases of postgastrectomy syndrome to the $\mathrm{Y}$-anastomosis had been performed with beneficial results. Subsequently, Schofield and Denton (1959) published their results obtained during an eight-year period using the $Y$-anastomosis in the treatment of duodenal ulcer. They again emphasized the risk of recurrent ulceration in the use of the $\mathrm{Y}$-anastomosis at the standard level Polya gastrectomy for duodenal ulcer.

It has been my practice to perform a Polya type of gastrectomy for all cases of peptic ulceration. Postoperative dumping syndrome is rare in males, and this is attributed to the fact that the afferent loop is always kept short as taught by C. A. Joll (1944, personal communication) and as restated by Stammers (1952, 1961) (Figs. A and B). In females, however, my results with this operation are not nearly so satisfactory as regards the dumping syndrome (cf. Capper, 1956). There therefore seemed to be a case for investigation of the Roux type of operation so far as incidence of anastomotic ulcer was concerned, especially since it appeared that it might give better results in female patients.

Schofield used the high measured gastrectomy of Visick (1948) in his series, but such high gastric resection is generally believed to be followed by serious loss of weight. Welbourn (1953) and Johnson (1948, 1954) agreed that the weight loss is often proportional to the amount of stomach resected. Capper (1956) suggested that for this reason not more than $70 \%$ of the stomach should be resected. Wells (1954) suggested that removal of almost the entire stomach (Schofield and Anderson, 1953) as a prophylactic against stomal ulcer may prove in terms of nutrition a high price to pay for immunity against anastomotic ulcer. He went on to suggest that recurrent ulcer in the Roux type of case is due to diversion of the alkaline pancreatic juice away from the stoma. Conservatism, therefore, regarding resection was considered to be of importance, and it was felt that as much stomach should be left behind as is compatible with avoidance of recurrent ulceration with the usual Polya technique in my hands. It was also felt that to meet Wells's objection the enteroanastomosis should be performed quite close to the gastroenterostomy. 